\title{
Polaridades expoliadoras: \\ La escritura sobre la colonización del cuerpo
}

\author{
Plundering Polarities: \\ Writing about the Colonisation of the Body
}

Ana Lúcia Sá

Centro de Estudos Africanos-ISCTE-IUL. Lisboa

\section{RESUMEN}

Este texto tiene como objetivo analizar la representación del cuerpo como una construcción verbal en tres novelas del escritor Castro Soromenho ( Chaga, Terra Morta y Viragem) que relatan el sistema colonial portugués en Angola durante el Estado Nuevo, bajo los regímenes de la asimilación y del trabajo forzado. Los cuerpos de los colonizados se representan socialmente como productos para ser utilizados, transformados y negados, constituyendo estos tres elementos procesos utilitarios e imaginarios basados en el concepto de "raza". En los textos seleccionados, se presentan las estrategias de desvalorización del ser humano a través de procesos simbólicos y escritos de deformación y despersonalización bajo la maquinaria colonial, como un sistema controlador del cuerpo y de las identidades.

Palabras Clave: Raza, Colonialismo portugués, Alteridad, Despersonalización

\section{SUMMARY}

The aim of this paper is to analyze the representation of the body as a verbal construction in three novels of the writer Castro Soromenho (A Chaga, Terra Morta y Viragem). They recount the Portuguese colonial system in Angola during the Estado Novo ( New State"), under the regimes of assimilation and forced labor. The colonized bodies are socially represented as products to be used, transformed and denied, a three element process based on the concept of race. In the selected texts, the strategies of belittling are presented through symbolic and written processes of deformation and dehumanization under the colonial machinery, considering the colonization as a system that controls the body and the identities

Key words: Race, Portuguese Colonialism, Otherness, Dehumanization 
Usted no conoce a los negros. Ahora los conocerá y verá que es una raza que no sirve para nada

(Terra Morta: 29)

Negamos al negro el hombre que es, sin ni siquiera pensar que, al negarlo, nos negábamos igualmente como hombres

(A Chaga: 140).

Y todos los negros se levantaban para saludar al hombre de piel clara, y todos los negros se callaban, y todos los negros se apresuraban en sus tareas.

(Viragem: 50$)^{1}$.

\section{EL CORPUS, TESTIMONIO DE LA COLONIZACIÓN DEL CUERPO}

Negar la humanidad a los negros afirmando la superioridad de los blancos es una dialéctica que caracteriza la colonización como un sistema de formulación identitaria a través de la categoría simbólica de raza. Así lo percibimos en las citas recogidas en este artículo, correspondientes a tres novelas del escritor Castro Soromenho ${ }^{2}$.

Terra Morta, A Chaga y Viragem, novelas publicadas en 1949, 1957 y 1970, retratan el sistema colonial portugués en la época del Estado Nuevo (1933-1974), en concreto tras la II Guerra Mundial y antes del inicio de la guerra de liberación de Angola, en 1961. El contexto se sitúa, de forma general, en Camaxilo, en la provincia de Lunda, al Noroeste de Angola, tratándose de un espacio doblemente periférico. En primer lugar, porque estaba alejado del litoral donde se situaba la capital de la colonia, Luanda, y, en segundo lugar, porque era periférico en la propia provincia, al estar ale-

${ }^{1}$ Versión original: “O senhor não conhece os negros. Agora é que os vai conhecer e verá que é raça que não presta" (Terra Morta: 29); "Negámos ao negro o homem que ele é, sem sequer pensarmos que ao negá-lo também nos negávamos como homens" ( $A$ Chaga: 140); "E todos os negros se punham de pé para saudar o homem de pele clara, e todos os negros se calavam, e todos os negros se apressavam nas suas tarefas" (Viragem: 50). Se procederá a esta misma modalidad a lo largo del texto, traduciéndose solamente las citas de las novelas analizadas. Todas las traducciones son de la autora.

${ }^{2}$ Castro Soromenho (1910-1968) es un escritor de origen europeo, nacido en Mozambique que se inserta en el marco de la concienciación política anti-colonial de la literatura angoleña, al denunciar el sistema colonial en la provincia de Lunda, sistema al que pertenecía, ya que fue funcionario administrativo en la región. Esto le permitió describir y denunciar los hechos que configuraban un sistema explotador y racista (sobre Castro Soromenho, ver Venâncio 1993: 49). 
jado de la Diamang, la compañía que detentaba la prospección diamantífera en la región. El poder colonial tenía un gran interés por esta explotación mineral tras la finalización de la trata de esclavos y el declive del comercio de productos como el caucho. Aún así, Lunda se considera como una zona geográfica marcada por la pasividad y el retraso: el "fin del mundo" de los colonos (Cf. A Chaga: 186; Terra Morta: 109).

Estas novelas deben considerarse fuentes de conocimiento sobre los procesos implicados en la colonización, de los cuales se destacará en este artículo, la colonización del cuerpo. Las obras de Castro Soromenho se consideran medios de interpretación del mundo social, porque ofrecen modelos para reflexionar sobre la realidad, concurriendo para la formación de un texto sociológico basado en la sociedad de referencia del escritor (Cf. Bourdieu 1996). En este caso, se trata de la formación de un texto sociológico a través de un corpus testimonio, emergido desde el interior de la propia maquinaria colonial ${ }^{3}$ portuguesa en Angola: a partir del texto se conoce la representación literaria del cuerpo de los colonizados propuesta por el sistema colonial. El discurso construye el mundo y es un aporte a la configuración de la memoria colectiva y a la creación de un imaginario simbólico e identitario. El texto deviene, así, sociedad, en la triple correlación entre la realidad, lo ficticio y el imaginario, pues, de acuerdo con Wolfgang Iser (1993), la producción de signos en el texto ficticio permite que en él se inserte la realidad extratextual y, a la vez, faculte la simbolización de la sociedad a nivel del imaginario.

En los textos seleccionados, se presentan las estrategias de desvalorización del ser humano a través de símbolos escritos de deformación y despersonalización, creados bajo la maquinaria colonial. Así los cuerpos de los colonizados se representan como productos que pueden ser utilizados, transformados y negados, constituyendo estos tres elementos procesos imaginarios, como explicité anteriormente. En esta dinámica, todas las figuras imaginadas y creadas de negros y de blancos materializan la diferencia colonial ${ }^{4}$, en un momento histórico de legitimación del gobierno colonial del Estado Nuevo que incluyó la creación de leyes basadas en la raza, a través de las cuales se ejercía el control de los cuerpos de los colonizados.

3 Utilizo esta denominación de acuerdo con el título de una novela del escritor angoleño Uanhenga Xitu, Os Sobreviventes da Máquina Colonial Depõem... que aborda los engranajes económicos y sociales del colonialismo portugués en Angola.

${ }^{4}$ Por "diferencia colonial" se entiende la institucionalización de diferencias de color o de género, por ejemplo, que se construyen para subalternizar al Otro no europeo (Cf. Maldonado-Torres 2007: 132-133). 


\section{POLARIDADES EXPOLIADORAS}

La colonización se percibe como un sistema de dominación del territorio, cuyos bienes son explotados y cuyos naturales son sometidos, poniendo en acción la dialéctica entre el cultivo, el culto y la cultura (Bosi 2003: 15-19). En este fenómeno totalizador, se persigue el control y el dominio de las identidades y del cuerpo de los colonizados, lo que se establece con la colonización moderna y capitalista llevada a cabo por las potencias europeas en América o África: era la colonialidad del ser. Si la modernidad es la otra cara de la colonialidad', de acuerdo con Santiago Castro-Gómez (2007: 79-80), ésta se basa en una estructura triangular compuesta por la colonialidad del poder, del saber y del ser, en un sistema que sigue vigente.

El poder se consagra en la dominación capitalista y en las clasificaciones jerárquicas que conducen a sistemas de explotaciones y de dependencias de unos sujetos por otros. En este paradigma modernidad/colonialidad, el concepto de "raza" se ha desarrollado como el factor esencial de distinción y de jerarquización -al que se añaden otros, como el género o el trabajo- fundamentales para comprender la colonialidad del ser y del saber, ya que, en este proceso histórico, se genera el hecho de que el concepto de Otro sea insertado en los valores de la modernidad eurocéntrica ${ }^{6}$ y se consagra el concepto de una supremacía capitalista blanca y patriarcal (Quijano 2007: 115-125; Maldonado-Torres 2007: 151).

En este marco se podrán analizar las relaciones de poder establecidas por los actores envueltos en el proceso colonizador portugués bajo el régimen dictatorial del Estado Nuevo. La colonización portuguesa del Estado

\footnotetext{
${ }^{5}$ De acuerdo con Ramón Grosfoguel (2006: 157), "la colonialidad y la modernidad constituyen las dos caras de la misma moneda", ya que la colonialidad corresponde a la creación del mundo moderno, basado en la jerarquización de diversas categorías, como el ser humano o la epistemología.

${ }^{6}$ La creación del concepto de Occidente debe ser entendida a través de la modernidad eurocéntrica, idea que permite categorizar a las sociedades usando un conjunto de imágenes que permite establecer un sistema de representación como occidental = urbanizado $=$ desarrollado; no occidental $=$ rural $=$ subdesarrollado. También facilita un modelo de comparación que establece las diferencias (entre estar cerca o lejos de patrones tenidos como occidentales) y provee criterios de evaluación valorativos (occidental $=$ urbanizado $=$ bueno; no occidental $=$ rural $=$ malo (Hall 1996: 186). Entre los principios de la modernidad eurocéntrica encontramos el principio jurídico del Estado-nación, el objetivo del progreso o el principio de la racionalidad, cuya expansión se basa en el principio de que el provincialismo europeo es universal (sobre la modernidad eurocéntrica, sus principios y su expansión, ver Amin 2006 y Lander 2002).
} 
Nuevo contempla mecanismos de control de la identidad y de la economía, interrelacionados, y materializados en la asimilación y en el contrato, dos grandes líneas de la misión civilizadora del régimen ${ }^{7}$. Esta se concretaba, no sólo en la política de poblamiento blanco de las colonias, sino también en el indigenato, la base legal de fijación de la discriminación social y política que distinguía entre civilizados e indígenas y que justificaba el trabajo forzado de estos últimos. El Estatuto dos Indígenas das Províncias da Guiné, Angola e Moçambique, aprobado en 1951 y revocado en 1961, contemplaba la división de la población, a partir de criterios raciales, entre indigenas (o nativos, incluyendo a los negros y mestizos "no civilizados") y civilizados (blancos y negros y mestizos asimilados). Los asimilados, a cuyo estatuto legalmente se podría acceder mediante pruebas o demostraciones, eran los negros y mestizos que se mostraban públicamente como civilizados, de acuerdo con los patrones coloniales ${ }^{8}$. Así escapaban del contrato, que estaba destinado a los indígenas, y que había sido introducido en 1926 como método de coacción para obtener mano de obra para la agricultura o la industria, tanto pública como privada, y que motivó migraciones forzadas dentro de cada colonia o de una colonia portuguesa a otra (ClarenceSmith 1990: 196). A través del trabajo forzado, el indígena se introducía en el progreso 9 y el pacto rural colonial obligaba a que los africanos participasen en la explotación de los recursos que la colonización les sustraía. En el fondo, este estatuto legitimaba al negro como un ser inferior en el seno de la sociedad colonial.

Como resulta claro, la raza, como concepto simbólico sin validez biológica, es un fenómeno central de la colonización de la tierra y de sus gen-

${ }^{7}$ En el Acto Colonial elaborado por António de Oliveira Salazar, Armindo Monteiro y Quirino de Jesus, en 1930, se asume la misión civilizadora de Portugal, justificada ideológicamente por la generosidad de elevar las poblaciones del imperio a un estadio superior de evolución asociado a Occidente (Cf. Castelo 1998: 45, 123; Caetano 1951: 32).

${ }^{8}$ En la obra Tradições, Princípios e Métodos da Colonização Portuguesa, Marcello Caetano (1951: 32-33) aclara que la educación, a la par que la cristianización, eran las claves para civilizar a los indígenas, siendo un principio básico de la colonización portuguesa la asimilación espiritual. Así, y de acuerdo con Elikia M’Bokolo (1985: 192), la doctrina de asimilación y de la integración caracteriza el régimen económico, político y social de Angola como parte de la nación portuguesa. Para que un negro o un mestizo fuera considerado asimilado, tenía que demostrar dominio de la lengua portuguesa, trabajar, vestir como un occidental o ser cristiano, entre otras exigencias (M'Bokolo 1985: 192-193).

9 De acuerdo con el Estatuto dos Indigenas da Guiné, Angola e Moçambique, compete al Estado hacer que el indígena reconozca que, por su trabajo, es indispensable al progreso, por lo que son forzados a trabajar siempre que sea necesario para el bien común, en obras públicas o privadas (C. Labisa 1958: 124-125). 
tes, ya que, como formación discursiva se implica en la lógica del poder. Desde la óptica del colonizador y de la creación del espacio colonial, se recurre a la consideración del vacío antes de la llegada de los europeos, de manera que, cuando ellos se vayan, se transformará en otro vacío, establéciendose un eje entre la ocupación de las tierras, legitimada por la colonización y la cultura obligatoria que domina la economía colonial de Lunda $^{10}$. La posesión de la tierra africana se racializa, así como las relaciones y el cuerpo de los actores sociales envueltos en este proceso. Además, en el desarrollo del programa de la modernidad y de su concomitante colonialidad, el cuerpo deviene un "objeto privilegiado de la deshumanización", con la inscripción de las diferencias de color o de género, entre otros factores de jerarquización ${ }^{11}$.

En una organización social colonial racista, los actores valen relacionalmente de acuerdo con el color de su piel. O sea, el color de la piel deviene valor y principio totalizador de la identificación, en un sistema basado en lo que puedo denominar polaridades expoliadoras. De acuerdo con el análisis presentado en este artículo, sostengo la idea de que las polaridades expoliadoras constituyen el concepto básico en la creación de las prácticas de la colonización del cuerpo. Estas polaridades expoliadoras se asientan en las oposiciones binarias centrales en la producción de significado que caracterizan el conocimiento eurocéntrico ${ }^{12}$ y que, en el contexto colonial, generan relaciones de poder —entendiendo por "poder" una manifestación de desigualdad que crea relaciones de sumisión ${ }^{13}$ - entre dos polos bien delimitados: el blanco-superior-civilizado-dominador y el negro-inferior-salvaje-dominado.

Estas polaridades no son, obviamente, categorías naturales, sino signos constituyentes de una gramática de dominación que consagra la cons-

\footnotetext{
${ }^{10}$ A Chaga: 120, 192; Terra Morta: 48; Viragem: 108-109.

${ }^{11}$ Según Maldonado-Torres (2007: 155). Entre las jerarquías se encuentran las de clase, de la división internacional del trabajo en centros y periferias, de etnia o de raza en que los caucasianos son privilegiados, de género, de la epistemología, con la valorización del conocimiento producido en Occidente o de lengua, según la cual las lenguas imperiales son preferidas (Grosfoguel 2006: 154-155).

${ }^{12}$ Los conceptos básicos del conocimiento eurocéntrico, de acuerdo con Edgardo Lander (2002: 246-247) son: la construcción repetida de oposiciones dispuestas valorativa y jerárquicamente (como la dualidad entre masculino y femenino o entre razón y cuerpo), aspecto que es determinante en esta consideración de las polaridades expoliadoras; la comprensión de la historia europea como universal y modélica para las demás; la conversión de las diferencias del Otro como valores, siendo la categoría de "raza" el instrumento de clasificación; la consideración del desarrollo tecnológico como el que lleva a formas superiores de conocimiento por el dominio del ambiente, etc.

${ }^{13}$ Esta definición de "poder" ha sido tomada de Iniesta (2001: 133).
} 
ciencia de la barrera entre ellas. Como afirma Premesh Lalu (2009: 38, 203), la gramática de la dominación elabora el proceso de cosificación de los sujetos coloniales a través de la combinación de un conjunto de aparatos que proponen mantener a los sujetos en el lugar que les es destinado por el poder colonial. Las acciones de este poder, como el saqueo, se enlazan con sus discursos y las denominaciones del colonizado como "primitivo" o "salvaje", haciendo que la norma impuesta por una gramática de la colonización sirva a los objetivos de control de toda la realidad colonizada, desde la económica a la social. La posición que los elementos ocupan en esta gramática normativiza estas polaridades expoliadoras para no crear inestabilidad en el mundo creado por la maquinaria colonial. El verbo colonial deviene acción y el concepto de "salvaje" es impuesto por esta gramática de dominación nacida en el seno de la violencia colonial.

Aimé Césaire, en su clásico Discurso sobre el Colonialismo (2006: 19-20), asocia estrechamente la colonización a la deformación del colonizado y del colonizador. En el seno de este proceso se encuentra la cosificación a la que el colonizador somete al colonizado, condición que deshumaniza a ambos.

El primer polo de esta relación es el que genera el segundo, expoliándolo de su humanidad a través de la atribución de características y, principalmente, de imágenes oposicionales en las que el negro es la categoría genérica que caracteriza a un conjunto de personas que habitan en determinado territorio (en este caso un espacio de la Angola colonial, que sirve como "África").

Es así cómo el concepto de "negro", tal como fue teorizado por Frantz Fanon, implica un carácter de no ser en las lógicas del discurso colonial; parcialidad humana emergida de la formulación que el dominador hace del dominado. "Le contexte colonial [...] se caractérise par la dichotomie qu'il inflige au monde", enuncia Fanon (2002: 48). En este sentido, el colonialismo, por la coordinación entre los vectores político y económico (visibles en la dominación, el control, la explotación con vistas al mercado), se presenta como un sistema social compartimentado y bipolar que consagra la dominación. La compartimentación, a la que se une la exclusión, es una característica que describe el mundo colonial, visible en la distinción entre zonas indígenas y europeas, entre el militar colonizador y el soldado colonizado, o en la creación de figuras intermediarias que entran violentamente en la vida de los colonizados, con la celebración de las obras grandiosas de los colonizadores (Fanon 2002: 41-43, 53). Es así cómo las identidades son proyectadas en la organización del espacio colonial, a cargo de los actores de este sistema. 
En el discurso de legitimación imperial, el colono se presenta como el héroe de la historia de Angola, el emprendedor y el conquistador del territorio (Ventura 1958: 116-117). En el fondo, es la imagen de propaganda personificada de la civilización. Por eso, los funcionarios de la administración creen que el negro reconoce en el blanco un ser superior ( $A$ Chaga: 87). Pero los colonizadores que vemos en las obras de Castro Soromenho se alejan de esta imagen de magnanimidad. Con algunos colonos se aprende que el colonizador es víctima del colonialismo, de la llaga que él supone y que es sentida por todos los actores que participan en esta dinámica ${ }^{14}$.

Los representantes de este primer polo en las novelas de Castro Soromenho son los comerciantes y los funcionarios de la administración. Éstos ensayan en la colonia el poder emanado de la metrópoli, basado en la subyugación a la dominación, con el objetivo de cumplir el pacto colonial del beneficio económico. La elite del cuadro administrativo se encuentra en la colonia para proteger y civilizar a los negros ( $A$ Chaga: 32 ), cumpliendo las tareas de recolectar los impuestos y de castigar (Viragem: 38-39). Son ellos los que ponen en escena la "doctrina de las tres $\mathrm{P}$-palo, pan y paño. [...] Con palo, paño y pan hemos construido un gran imperio" (A Chaga: 98 $)^{15}$.

El palo es el vértice de esta doctrina triangular que se hace más presente en las novelas. Es el signo de los instrumentos que sirven para educar - o subyugar-, como el látigo o la palmeta. En fin, sirve para que la administración accione el biopoder o el necropoder, tal como Achille Mbembe (2003) lo concibe, como la salvación de los pueblos de sí mismos a través, por ejemplo, de la asimilación o de la violencia física que, no raramente, resulta en la aniquilación. Los instrumentos de este necropoder se utilizan para, de una forma inmediata, castigar el cuerpo de los colonizados públicamente y, después, establecer una relación dialéctica entre el espacio público de castigo y de ejemplo, y el espacio cerrado que simboliza la institución colonial. Esta dialéctica se mide a través de los fluidos del cuerpo de los colonizados, en concreto de la sangre, que va - en público- de sus cuerpos a la tierra y se carga en el látigo o en la palmeta lle-

${ }^{14}$ El personaje paradigmático de la consciencia de que el colonizador deviene inhumano y víctima de un sistema que le impone como explotador es Lourenço, de la novela $A$ Chaga. Él había comerciado con esclavos y otros bienes (como marfil) hasta que comprendió que el negro era un ser humano y que él mismo formaba parte del sistema que le negaba esa humanidad: "Nada justificaba estar en contra del hombre. Nos hundimos en el pantano y nadie se quiere salvar" (Nada justificava ser-se contra o homem. Afundamo-nos no pântano e ninguém se quer salvar" [A Chaga: 140]).

15 "doutrina dos três $\mathrm{P}$-pau, pão e pano. [...] Com pau, pano e pão construímos um grande império" ( $A$ Chaga: 98). 
vados por los castigadores en el interior del edificio que institucionaliza la colonización, haciendo que el resultado de los castigos sobre los colonizados en el espacio público repercuta en el espacio de la toma de decisiones de la colonización local (por ejemplo: A Chaga: 91-94).

La violencia deviene medio de domesticación del cuerpo del colonizado y se basa en la premisa del cuerpo salvaje y de la supremacía blanca en tierra de negros. "Negros y mosquitos por todas partes, como una plaga" ${ }^{16}$ ( $A$ Chaga: 5): resumen de África para el personaje Joaquim Mota. La tierra se mezcla con la cultura del colonizado, sobre la cual las autoridades coloniales ejercen el poder de negarla o de aprovecharla.

Se asiste a la prohibición de cantos (Terra Morta: 50, 94) o al desprecio de la palabra del africano (Viragem: 67-69). Pero, a la vez, se detecta un aprovechamiento de la diversidad que compone la nación colonial portuguesa, de los trajes típicos, de los instrumentos musicales en ceremonias conmemorativas del imperio, aunque quien ejerza el folclore sea salvaje, en unas ceremonias puestas en escena por las propias autoridades coloniales, quitándole la carga cultural, como es el caso de las danzas guerreras lunda ${ }^{17}$.

En este ejercicio del poder, el segundo polo de las polaridades expoliadoras - lo que ha sido expoliado de su humanidad- se constituye, en el lenguaje usado por los colonos, en los negros, los pretos o negralhada ${ }^{18}$, adjetivos que sirven para definir los seres humanos y toda su dimensión social y cultural. La desvalorización de su humanidad se hace, no sólo por la negación o por la ausencia de características, como en los siguientes ejemplos: “aquí negro es negro, sólo negro, nada más" (Terra Morta: 30) ${ }^{19}$, o "El colonizador nunca ha considerado el negro como un hombre. Es monstruoso" (A Chaga: 190 ${ }^{20}$. La desvalorización se hace también esencialmente por la evidente terminología de construcción y fijación de la realidad, que se repite en la manera de reproducir y cristalizar una imagen de salvajismo y de animalidad. El mundo colonial es maniqueo y es en él donde el colonizador transforma al colonizado en un ser sin valores y a su sociedad en una sociedad sin ética. Este maniqueísmo animaliza al colonizado y hace que se descubra al animal porque así es nombrado (Fanon 2002: 45-46). Así se construye, del lado del colonizado, la epidermización interiorizada de la inferioridad (Cf. Fanon 1952: 8).

\footnotetext{
16 "Negros e mosquitos por toda a parte, como uma praga" ( $A$ Chaga: 5).

${ }_{17}$ A Chaga: 4-7, 23-24, 51-51, 80-83; Viragem: 179, 195-197.

${ }^{18}$ A Chaga: 5, 138; Terra Morta: 59, 65-66; Viragem: 85, 145, 222.

19 "aqui o negro é negro, só negro, nada mais" (Terra Morta: 30).

20 "O colonizador nunca considerou o negro como um homem. É monstruoso" ( $A$ Chaga: 190).
} 
Ser negro corresponde a ser un niño grande o a pertenecer a una raza inferior (A Chaga: 11). Y el polo que expolia de humanidad lo hace a través de la comparación con animales: los negros son cerdos (A Chaga: 4), perros (Viragem: 17) o bueyes (Terra Morta: 80). Además de perezosos (A Chaga: 87), alcohólicos (A Chaga: 191), ladrones (Viragem: 166) o libertinos (A Chaga: 88), entre tantas otras características que, en el fondo, encuentran la síntesis en la palabra salvajes ( $A$ Chaga: 87; Terra Morta: 226; Viragem: 4-5, 158). Y entre negros, se reproduce el discurso del colono en una clara demostración de la reproducción de la potente colonialidad del $\operatorname{ser}^{21}$, al ser tratados como salvajes (A Chaga: 44; Terra Morta: 180; Viragem: 158).

En todos estos ejemplos, el ser humano se equipara a hombre y, como tal, la categoría negro aparece masculinizada. La generalización se hace en el masculino y, aquí, deriva del hecho de que son hombres (y blancos) los que dominan y los que determinan los ejes de las denominaciones y del juego de las imágenes oposicionales que les separan de los negros. Y ser negro es su característica, más allá de otros tipos de identificación, como la pertenencia a una comunidad de lengua y cultura. El colonizador otorga al colonizado una identidad, punto de partida para la construcción del estereotipo que pretende la deformación, la simplificación y el control de la realidad ajena que se quiere transferir para la totalidad de la realidad colonial. Así, la categoría racial genérica es la catalogación primera de pertenencia, de la cual se ramifican otras descripciones y otras valoraciones, como hemos visto en los ejemplos anteriores.

La construcción de la alteridad en el discurso colonial se fija a través del estereotipo, construido en las novelas a través de la comparación y de la adjetivación, que radica en el pre-concepto y tiene como objetivo la deformación, de cara a controlar la realidad ajena, pero que se encuadra en la lógica colonial basada en el mantenimiento de la diferencia racial ${ }^{22}$.

\section{CUERPO NEGRO = CUERPO UTILITARIO, CUERPO TRANSFORMADO, CUERPO NEGADO}

Desde el punto de vista de la utilización del cuerpo como útil para el trabajo, aliado a su deshumanización, surgen en las novelas dos categorías

${ }^{21}$ O, como concluye Frantz Fanon (1952: 182): "Le Noir, à certains moments, est enfermé dans son corps".

${ }^{22}$ Al final, estamos delante de "le nègre esclave de son infériorité, le Blanc esclave de sa supériorité, se comportent tous deux selon une ligne d'orientation néurotique" (Fanon 1952: 48). Sobre la construcción de estereotipos, ver Bhabha (1995: 66-67). 
de negros: el esclavo y el contratado. Sus cuerpos son instrumentos de trabajo que se reducen a una dimensión económica, racializada y privada de su dimensión social. El esclavo es un recuerdo del pasado de los comerciantes cuando eran los agentes de la penetración colonial en el interior. En las novelas, pertenecen apenas a la memoria individual de los más antiguos colonos en la región. A los esclavos se les llamaba moneda de la región agreste, oro negro o ébano ${ }^{23}$. Su sustituto es el cabeza de alquitrán (Terra Morta: 95), el contratado, una versión actualizada en el Estado Nuevo colonial del símbolo corporal del ser humano como "mercancía cuantificable con un precio" (Dussel 2010: 330). Este régimen de contrato puede considerarse como un sistema legal de legitimación racial de la utilización del cuerpo que permite concluir sobre la instrumentalidad del cuerpo colonizado para el beneficio de la colonización. En las palabras del angoleño Mário Pinto de Andrade (1975: 12), destacado nacionalista, el contrato ha sido una vasta empresa de cosificación.

Los contratados son negros violentamente privados de libertad en nombre del trabajo voluntario ( Chaga: 92). Alejados de sus familias, son tomados como un valor de negocio en un modelo de producción de rentabilidad colonial ${ }^{24}$. A este sistema de coacción pertenecen aún los sipaios y los capitas, dos categorías de miembros integrantes de la fuerza policial colonial que se constituyen en identidades creadas por el sistema colonial, ligadas a la raza. Desde la perspectiva del colonizador, estas identidades se destinan a los negros, pero, desde una perspectiva situada en la comunidad de lengua y cultura, no tienen que ver con el color de la piel, sino con dos factores: el origen étnico y la función desarrollada en el sistema explotador. Para los habitantes de la comunidad tchokwe, "la fuerza del blanco es el lunda y la escopeta" ( $A$ Chaga: 92 ), despreciando a los miembros de la comunidad lunda que había sido sometida por los tchokwe antes de la implantación colonial de facto en la región y que servían al régimen colonial como soldados ( Chaga: 29).

La indumentaria les permite una presentación social del cuerpo distintiva en relación con los demás negros, con los que comparten los pies descalzos $^{25}$. Los sipaios portan uniforme de color sal y pimienta, casco rojo,

${ }^{23}$ A Chaga: 67, 130-131, 140, 146, 149; Terra Morta: 46.

${ }^{24}$ Para los colonizadores, el contrato es la única forma de hacer que los negros trabajen. O sea, es su medio de obtención de mano de obra gratuita. Además, el contrato, como la recolección de impuestos, beneficia a los jefes de la administración, que con ellos se lucran al margen del sistema (A Chaga: 13, 18, 35, 45-46, 91, 121, 218-220; Terra Morta: 33, 42, 91; Viragem: 14-15, 125.

${ }^{25}$ Los zapatos simbolizan prestigio en la estratificación social racial de este contexto. 
látigos y armas. Los capitas, de ellos dependientes, comparten el casco y los látigos, pero no las armas y el uniforme ${ }^{26}$. Los símbolos que utilizan los caracterizan, y usan el poder que el colonizador les otorga para ejercer el control sobre el cuerpo utilitario de los demás colonizados, como los contratados que intentan escapar, a los que castigan con brutalidad ( $A$ Chaga: 91; Viragem: 14-15) o los indígenas que no quieren pagar impuestos (Terra Morta: 49). Esta fuerza colonial de africanos negros servía de intermediaria entre el mundo del colonizador y el del colonizado. O sea, intermedian entre las necesidades estipuladas por la administración colonial, como el reclutamiento de trabajadores para el contrato, y la población que va a satisfacerlas. Con todo, no son considerados por ninguno de los mundos a los que sirven de eslabón, ya que son despreciados por el poder colonial, el real detentador del poder y al cual siempre intentan agradar a través de la violencia verbal y física sobre los negros, y por los demás negros, que les tildan de negros del gobierno o de perros de los blancos ${ }^{27}$. Una de sus tareas era la recluta, por medios violentos, de hombres para la contratación, llevada a término en aldeas y cuya regulación estaría a cargo de las autoridades tradicionales, o sobas.

Las autoridades tradicionales detentan un poder sobre las tierras y sus habitantes de origen sagrado, procedente de los ancestros, constituyendo el modelo de mando de la sociedad que representan. En este poder se manifiesta la representación del grupo y el garante de la cohesión social ${ }^{28}$. En estas autoridades recaía el control de comercio en las regiones alejadas de los centros de administración colonial, y los comerciantes les pagaban impuestos que les permitían hacer negocio ( $A$ Chaga: 138, 225; Terra Morta: 46). En la novela Terra Morta, era con el soba Xá-Mucuari con quien negociaban los viejos comerciantes. Y eran los comerciantes apenas los únicos blancos con los que se relacionaba este soba; jamás se subyugó a las autoridades coloniales. Con la intensa penetración colonial, él se suicidó junto a los símbolos de los antepasados, restituyéndose así a la tierra ancestral.

Esto es visible, por ejemplo, en la siguiente observación: "el mulato descalzo era igual a cualquier negro de aldea" ("mulato descalço era igual a qualquer negro da senzala" $[A$ Chaga: 44]).

${ }^{26}$ A Chaga: 19, 30; Terra Morta: 33, 83, 91-92; Viragem: 15, 24, 40, 94, 96, 145, 159160, 166-169. El capita viste "paño amarillo en la cintura, jersey con rayas rojas y azules, y casco en la parte superior del pelo ensortijado" "pano amarelo aos quadris, camisola às riscas encarnadas e azuis, e cofió no alto da carapinha" [Terra Morta: 33]).

27 Terra Morta: 49, 59; Viragem: 15, 24, 93, 137, 142.

${ }^{28}$ Sobre las autoridades coloniales en África, ver Iniesta (2001: 113) o Dias (2000: 40-50). 
Su dignidad se presenta opuesta a la indignidad de Comboio, su sustituto escogido por la autoridad colonial ${ }^{29}$.

Si en el pasado "un soba era un rey" ( $A$ Chaga: 29) $)^{30}$, en el presente narrativo de las obras se refleja la legislación portuguesa que consideraba la homologación de las autoridades coloniales por los administradores europeos de los que recibían órdenes (Caetano 1951: 46). Eran igualmente intermediarios entre los objetivos económicos del colonizador y la sociedad colonizada, reclutando contratados, por ejemplo, y esta ruptura implica la ausencia de reconocimiento por parte de la población y el mensaje claro de que la tierra ya no pertenecía a los africanos ${ }^{31}$.

Incluso en la indumentaria se percibe la influencia de la colonización en la presentación social del cuerpo en este grupo ${ }^{32}$. En una estrategia de ridicularización de la colonialidad del ser de los que desean agradar a las autoridades coloniales, el ya citado Comboio, que domina mal la lengua portuguesa, se hace distinguir socialmente por una indumentaria que mezcla objetos de origen local e importados: "El soba Comboio, de paño nuevo en la cintura, apretado en un dolmán de oficial de la antigua Guardia Municipal, con un paraguas abierto, lleno de agujeros y de varillas rotas" (Terra Morta: 217$)^{33}$. Se presenta así para tratar con un comerciante perteneciente al grupo de colonos que más tiempo lleva en Lunda y que resulta esencial para comprender el papel de las mujeres y de los mestizos o mulatos en el sistema colonial presentado en las novelas de Castro Soromenho.

Las relaciones que los colonizadores — funcionarios de la administración o comerciantes - tienen con mujeres negras muestran el sistema discriminatorio colonial que mezcla raza y género, y se observa en el dominio por

29 Terra Morta: 217- 218. El jefe de la administración es el responsable de la selección del nuevo soba, por considerarlo aliado de los blancos, yendo en contra de los ancianos de la comunidad. Por esto, el administrador concluye: "Pues es este mismo el que nos sirve para soba" ("Pois é esse mesmo que nos serve para soba" (Terra Morta: 150).

30 "Um soba era um rei" ( $A$ Chaga: 29).

31 A Chaga: 14, 225; Terra Morta: 49, 59, 133; Viragem: 145.

32 El cuerpo transmite signos que se materializan en la indumentaria o en otros elementos definitorios determinados, por ejemplo, por un estatus en el grupo (sobre este sentido de presentación del cuerpo, ver Howson 2004: 19). La indumentaria específica de las funciones de autoridad tradicional, o algunos objetos, son adoptados por los sobas para que simbolicen su estatuto de elite, por ejemplo, las pipas (Terra Morta: 133; Viragem: 105) o los asientos (Viragem: 105).

33 «O soba Comboio, de pano novo à cinta, apertado num dólman de oficial da antiga Guarda Municipal, com um guarda-chuva aberto, cheio de buracos e varetas quebradas" (Terra Morta: 217). 
la utilización sexual. Ambos grupos comparten dos procesos de "des-generacción" (siguiendo a Maldonado-Torres 2007: 156) del cuerpo de las mujeres negras subordinadas.

En primer lugar, y para los funcionarios de la administración colonial, la mujer negra, en particular la joven, es solamente objeto de deseo sexual ( $A$ Chaga 73-77; Terra Morta 86-87). Por lo que respecta a los comerciantes, las relaciones con las mujeres negras adquieren un grado de complejidad más allá de este uso del poder dado por la pertenencia a la administración para beneficios sexuales. Ellas son las compañeras de los comerciantes y con ellas tienen hijos, hecho que adquiere matices diversos en cuanto a la construcción de modelos de familia o de privilegio racial, como veremos más adelante.

El segundo proceso que acciona la desconsideración de la mujer negra es la primacía que las mujeres blancas tienen en el imaginario masculino, relacionada con una supremacía masculina en la construcción de imágenes de blanquitud que sirven para conjugar la estratificación social colonial ( $A$ Chaga: 2-3; Terra Morta: 172). La blanquitud se asocia a la identidad moderna, y los no blancos logran esa identidad a través de la demostración de que se aproximan a lo que se asocia a ser blanco (sobre la identidad moderna y la blanquitud, ver Echeverría 2007).

Los estereotipos centrados en la raza y en una diferenciación de género, combinados, mantienen un sistema discriminatorio (Bhabha 1995: 66-67). El inicio de la vida sexual de una mujer negra, de acuerdo con los colonos, es un factor de diferencia en relación a las blancas. Y es así porque "Son negras. Ellas empiezan con eso con menos de diez años" (A Chaga: 9) ${ }^{34}$. Las mujeres blancas tienen un estatuto social y simbólico superior ${ }^{35}$ y sólo con ellas es admisible el matrimonio. Se excluye el casamiento con una mujer negra, así como sus derechos como compañeras de toda la vida de los comerciantes, sin que puedan quedarse con la casa después de la muerte de su hombre blanco ${ }^{36}$. En la construcción discursiva y social de estas relaciones, el prestigio emerge de la raza y no de la clase, como se percibe en la siguiente cita, de la voz del comerciante Paulino: "ie Casarme con una negra, yo?! [...] Pobre, sí, pero blanco" (A Chaga: 122) ${ }^{37}$.

La graduación de las distinciones va más allá e implica a mujeres blancas, mestizas y negras. Si las primeras son "para casarse", las segundas po-

\footnotetext{
34 "São negras. Elas aqui começam nisso com menos de dez anos" (

35 Aunque en los textos literarios sean presentadas como crueles y sin capacidad de generar vida (A Chaga: 60-61; Terra Morta: 40; Viragem: 10-11, 14-15, 22-23, 46, 49).

36 A Chaga: 105-108, 122, 210; Terra Morta: 194.

37 "Casar com uma negra, eu?! [...] Pobre, sim, mas branco" (A Chaga: 122).
} 
drán implicar contrariedades en el ejercicio del poder masculino y las terceras serán las mejores para utilizar su cuerpo como objeto y como instrumento de trabajo:

Para cordera, la negra es mejor. Con las mulatas tenemos que tener más cuidado, el padre es blanco, mete civilización, follones, jel diablo! Las negras no importan a nadie, se las toma y se las suelta (Viragem: 222-223) ${ }^{38}$.

En estos ejemplos percibimos que la colonialidad del ser se hace aguda en las relaciones inter-raciales en este contexto colonial, matiz que por cierto no ha sido tomado en consideración por Gilberto Freyre en su proposición teórica del luso-tropicalismo (Freyre 1966), cuando aboga por la predisposición del portugués para la colonización híbrida por su condición identitaria bicontinental, fluctuante entre Europa y África, con una mayor propensión que los demás a la mezcla, aunque en el contexto de la colonización basada en la trata de esclavos, central en la construcción del Brasil colonial (Freyre 2003: 66-73) ${ }^{39}$. Así nace el mito de la creación de un mundo diferente por la disposición a aceptar al Otro (Klobucka 2008: 471-472). Uno de los espectros del luso-tropicalismo es la consideración del diferencial de la colonización portuguesa, que todavía subsiste en el imaginario, al que subyace la idea de que no existía una separación definida por la idea de raza. Incluso en un artículo publicado en 1966, "Interação eurotropical: aspectos de alguns dos seus vários processos, inclusive o lusotropical", Gilberto Freyre defiende que los agentes de la colonización portuguesa proceden a una interacción integradora y no de repudio con los autóctonos, y que el proceso luso-tropical no favorece la discriminación, sino la aproximación de poblaciones de orígenes distintos. Sin embargo, las novelas de Castro Soromenho, entendidas como construcciones discursivas del colonialismo portugués en la angoleña provincia de Lunda, abren espacios y temas silenciados en este diferencial de la colonización portuguesa.

\footnotetext{
38 "Para borrega a negra é melhor. Com mulatas a coisa fia mais fino, o pai é branco, mete civilização, encrencas, o diabo! De negras ninguém quer saber, a gente pega e larga" (Viragem: 222-223). En la novela $A$ Chaga leemos la misma construcción de la identidad de las mujeres: "Para amigar la negra es mejor, [...] trabaja en la tierra y en casa, ayuda al hombre. Ella aguanta todo y se contenta con poco, con lo que se le da. La mulata no, exige ropa fina y perfumes. Y quieren comer a la mesa con plato y tenedor" ("Para amigar a negra é melhor, [...] trabalha na terra e na casa, ajuda um homem. Ela aguenta tudo e contenta-se com pouco, com o que se lhe dá. A mulata não, exige roupa fina e vidros de cheiro. E querem comer à mesa com prato e garfo") ( $A$ Chaga: 133).

${ }^{39}$ De acuerdo com Gilberto Freyre, en Casa Grande e Sanzala, a pesar del sistema racista esclavista, el portugués ha sido el "colonizador europeu que melhor confraternizou com as raças chamadas inferiores" (Freyre 2003: 265).
} 
Considerando la miscibilidad de los portugueses, José Paulino, un comerciante de A Chaga, defiende que "hacer hijos mulatos sí es colonizar; colonizar a la portuguesa" ( $A$ Chaga: 136$)^{40}$. Pero el mestizaje era inaceptable desde el punto de vista político y fue condenado en el I Congreso Nacional de Antropología Colonial (Porto, 1934). Se consideraba una "práctica reprobable y a evitar", desaconsejándose los contactos sexuales entre razas distintas. Se aducía que el mestizaje tenía consecuencias negativas y que los mestizos eran biológicamente inferiores (Castelo 1998: 111).

En las novelas de Castro Soromenho, los mulatos son hijos de la violencia simbólica de relaciones desiguales y, por eso, revelan un proceso de despersonalización materializado en los sentimientos que nutren sus progenitores: el odio al padre blanco y la vergüenza de la madre negra ( $A$ Chaga: 114). Tal como está ensamblado, el sistema social y simbólico colonial no deja lugar para los mulatos, que no pertenecen ni al universo paterno ni al materno. O sea, ni al blanco ni al negro, en el tejido de ambigüedad creado por el sistema colonial.

El padre blanco utiliza a los hijos como fuerza de trabajo y no deja de recordarles que son negros y no blancos:

A nuestra gente no le gusta el mulato que quiere ser blanco. El color es lo que manda. El mulato no puede hacerse blanco. ¿Qué te dice el blanco cuando te mira la cara? Café con leche, dice. Cuando se enfada te llama cerdo. Al blanco no le gusta el mulato, no ( $A$ Chaga: 211) $)^{41}$.

La madre negra manifiesta un discurso opuesto, que no deja de marcar el sistema que construye la polarización entre la barbarie y la civilización basado en el color de la piel, el primer signo del discurso racialista:

Tú eres hijo de blanco. Yo te he parido en su casa. No eres un cualquiera, no (Terra Morta: 72$)^{42}$.

Pero el mestizo era considerado negro en la sociedad colonial. El negro como un no ser que desea ser blanco (para ser ser), es la idea central

\footnotetext{
40 "fazer filhos mulatos é qu'é colonizar, colonizar à portuguesa" (A Chaga: 136).

${ }^{41}$ Señálese que, en las novelas, siempre que se hace hablar a un personaje no blan$\mathrm{co}$, se inscribe la diferencia colonial a través del dominio deficiente de la lengua portuguesa, como en este caso, cuyo original es "Nossa gente não gosta mulato quer ser branco. Cor é que manda. Mulato não pode ficar branco não. Qu'é que branco fala olhando tua cara? Café com leite, ele diz. Quando zanga te chama grunho. Branco não gosta mulato não" ( $A$ Chaga: 211).

42 "Tu é fio de branco. Eu pariu você na casa dele. Não é um calquer, não" (Terra Morta: 72).
} 
del libro Peau Noire, Masques Blancs (1952), de Frantz Fanon, a partir de la cual se ramifican modelos de análisis sobre las relaciones entre negros y blancos, y sobre la psique del negro en contextos de colonialidad, partiendo de su Martinica natal. La ideología transmitida por las madres negras de los hijos de blancos se encuadra en uno de estos modelos: el deseo de blanqueamiento por la proximidad al hombre blanco (Fanon 1952: 44). Pero, tras la oposición al matrimonio y a compartir patrimonio de los compañeros blancos, podremos concluir que este estatuto de proximidad otorga a estas mujeres un grado mayor de subordinación que mezcla raza y género en el seno de la máquina colonial que les da un lugar subalterno cristalizado. Además, y aunque el color de la piel sea la base primera de identificación, ser blanco implica más que este factor, extendiéndose a la forma de comportarse públicamente, a la indumentaria o a la posibilidad de comprar bienes que connotan europeidad.

Frantz Fanon trata en su libro (1952) la deformación psíquica del ego de los negros que quieren parecer blancos, y es en este esquema de presentación social donde se incluye el cuerpo. La imitación, en este contexto, se construye por la despersonalización y por la diferencia en exceso, como la trata Homi Bhabha (1995: 86, 90, 111), ya que la discriminación basada en el color de la piel no deja de producirse.

En las obras de Castro Soromenho no encontramos a negros asimilados como categoría jurídica del sistema colonial portugués. De todas formas, la asimilación impuesta por el sistema se percibe, por ejemplo, en la indumentaria como presentación social del cuerpo. En este tópico también se percibe la racialización del sistema colonial, pues el vestuario se asocia a una determinada categoría social y racial que tiene explícita la producción de diferenciaciones discriminatorias. O sea, la raza es un factor que determina la forma de vestir de los personajes:

Se está quedando blanco. Calzado y con calcetines, jei! Casco de blanco, jui! Su cara misma cara es blanca ( $A$ Chaga: 179$)^{43}$.

En el caso de la doble diferenciación de género y de raza, las mujeres blancas visten ropas occidentales, hecho que comparten con las mestizas hijas de los comerciantes. Las madres de estas visten paños y van descalzas, tal como las mujeres tchokwe, que exhiben con orgullo los signos de pertenencia a su comunidad, como los senos aplanados y los adornos. A través de estas cuatro categorías de personajes femeninos, comprendemos que también el vestuario se asocia a la combinación entre raza y género.

\footnotetext{
43 "tá ficando branco. Sapato no pé com meia, ei! Capacete de branco, ui! Cara dele é mesmo branca" (A Chaga: 179).
} 
Y, una vez más, la categoría ideológica de "raza" determina la asociación entre un color de piel y un lugar en la sociedad colonial polarizada, mediante el vestuario, igualmente visible en la distinción hecha entre funcionarios blancos y negros de la administración colonial. Los soldados negros comparten con los demás colonizados el hecho de vestir paños, signo que, desde la cosmovisión del colonizador y de la inserción de los colonizados en el seno de la civilización occidental, es preferible a las pieles de animales que usan los demás indígenas ${ }^{44}$.

\section{VIDA EN PARALELO Y CATEGORÍAS DE CUERPOS COLONIZADOS}

La vida en el contexto colonial representado en las novelas de Castro Soromenho es mostrada en paralelo: entre colonizados y colonizadores, entre funcionarios y comerciantes, entre nuevos y antiguos colonos, entre agentes africanos de la colonización e indígenas y, dentro de estos, entre hombres y mujeres, entre negros y mulatos.

La compartimentación se pone de manifiesto en la forma en que los dos polos no se tocan, exceptuando cuando el colonizador necesita del colonizado para obtener beneficios económicos. Cada grupo tiene un lugar vivencial distinto: el espacio se divide entre la población de los administradores, la de los comerciantes, la de los sipaios y capitas, y las demás, habitadas por los indígenas y alejadas de este centro (A Chaga: 1-2; Terra Morta: 33-34; Viragem: 195).

Un episodio narrativo de la novela $A$ Chaga, que considero paradigmático de la paralelización de la vida social colonial y de la desvalorización del negro, es la ceremonia fúnebre de Alice, la compañera del viejo comerciante Lourenço. Esta existencia en paralelo se muestra en términos de modelos religiosos, en términos de rituales y en términos de la clara distinción entre el blanco y el negro. Alice, antes de vivir con Lourenço, se llamaba Caçula y vivía con Gunga. Pero las relaciones entre los dos hombres se enmarcan en la violencia que el sistema colonial presupone, metaforizada en la toma de la tierra perteneciente al africano y de todos los bienes que de ella nacen, por el trabajo del hombre que se descubre colonizado:

${ }^{44}$ Los ejemplos del vestuario de los personajes en las novelas de Castro Soromenho se encuentran en $A$ Chaga: 73-74, 179 y Terra Morta: 33, 69, 144. Al respecto del vestuario hecho de pieles de animales, el administrador colonial desdeña a un grupo de gente mayor, "preguntándoles si no tenían vergüenza de ir así vestidos con pieles, a oler mal como los animales, en vez de trabajar para comprar paños y jabón" "perguntandolhes se não tinham vergonha de andar assim vestidos com peles, a cheirarem mal como os bichos, em vez de trabalharem para comprar panos e sabão" [Terra Morta: 151]). 
Le tomó la mujer y la tierra, pero ordenó que le entregara el maíz y las calabazas que en ella encontrara ( $A$ Chaga: 3$)^{45}$.

La ceremonia que se oficia en el fin de la vida de la que pasó a llamarse Alice, se hace con símbolos cristianos, como las velas o el rosario, en la casa del colono, rodeada por blancos, sus mujeres negras y sus hijos mestizos. No hay lugar para celebrar a sus dioses, ni hay lugar para que el resto de la ceremonia fúnebre se haga de acuerdo con las prerrogativas que implicaría ser mujer de blanco. La muerta se enterró envuelta en una tela y no dentro de un ataúd ${ }^{46}$, en el cementerio de los africanos y no en el de los blancos, en una "tierra desnuda resguardada de los matorrales por altas estacas, junto al terreno vallado por un muro blanco reservado para las tumbas de los europeos" (A Chaga: 105 $)^{47}$.

Esta breve exposición sobre la existencia en paralelo de los universos negro y blanco que componen la estructura colonial, es otra demostración de que la condición de ser solamente era concedida a los blancos. Y la interiorización de esta construcción ideacional por parte del grupo constituido por negros y mestizos revela que con la colonización se creó un concepto de persona basado en prejuicios, así como la reproducción de la colonialidad del ser en el seno de los que son considerados inferiores por el colonizador. La construcción discursiva de la diferencia colonial se repetía en el grupo de los colonizados: para los mestizos, los negros eran inferiores, no civilizados, salvajes; entre negros se estilaba el uso de adjetivos relativos al salvajismo y a la animalidad ${ }^{48}$.

Entre el vasto grupo de los colonizados se reproduce la consciencia de

45 "Tomara-lhe a mulher e a terra, mas mandara-lhe entregar o milho e as abóboras que nela encontrara" ( $A$ Chaga: 3 ).

${ }^{46}$ Esto motiva un comentario de Serafina, compañera negra de un comerciante: "Tantos años con Alice, haciéndole hijos en su vientre, comiendo juntos pirão [comida elaborada con harina de yuca], y la deja en un hoyo sin ataúd, como un animal. Una persona no es un perro, no lo es" (Faz tantos anos com Alice, fazendo filhos na barriga dela, comendo pirão junto, e mandou ela no buraco sem caixão, como bicho. Pessoa não é cão, não é não" [A Chaga: 108]).

47 "terra nua defendida do matagal por alta e forte estacaria, do outro lado do talhão murado de branco reservado às campas dos europeus" ( $A$ Chaga: 105).

48 Tal y como se observa en los siguientes ejemplos, el primero en palabras de un mestizo y el segundo de un negro: "El mestizo no es negro, no. Se le metió la sangre de blanco ya hace tiempo. El negro es carbón. El carbón es tosco" (Fulo não é preto não. Sangue de branco ficou faz tempo. Preto é carvão. Matumbo é qu'é carvão [ $A$ Chaga: 207]); un soldado negro trata a otro por "sarvaje" (en portugués corrompido: "servage") y el administrador le recuerda que "Salvaje lo eres tú, animal!" ("Selvagem é tu, minha besta!" [Viragem: 158]). 
pertenencia a lugares fijos dentro del sistema, de la existencia de escalas de valoración que reproducen la gramática de la dominación colonial, basada en el presupuesto del derecho y del ejercicio del control sobre las tierras y su población. Y si queremos comprender sistémicamente el hecho colonial, es necesario subrayar los mecanismos de colonización de los cuerpos y de las identidades, los cuales se basan en la construcción y la repetición de las polaridades expoliadoras que fundamentan el mundo colonial y la violencia simbólica que controla la disposición jerárquica de las relaciones establecidas de acuerdo con el color de la piel y con el estatus derivado de las presentaciones socio-raciales.

Al final, se trata de la imposición exógena de construcciones identitarias que se marcan en el cuerpo de los colonizados, tal como hemos visto en este artículo respecto a muchas construcciones basadas en el concepto primordial de raza, instrumento fundamental de la violencia simbólica y real por la cual el sistema colonial se impone. En esta imposición exógena, se construye el mundo blanco, siguiendo a Frantz Fanon, en lo que "l'homme de couleur rencontre des difficultés dans l'élaboration de son schéma corporel. La connaissance du corps est une activité uniquement négatrice. C'est une connaissance en troisième personne" (Fanon 1952: 89).

Asociándose la producción y el poder, el cuerpo de los colonizados deviene utilitario y económico, privándose de su dimensión social. En este contexto, devenir persona se hace por el trabajo forzado, inscrito en el progreso que, por la obra colonial, elevará los no seres a seres. Incluso desde este punto de vista utilitario sobre el cuerpo, son imprescindibles las perspectivas generales dicotómicas en las que la raza es el concepto central, donde radican las estrategias discursivas por las cuales se atribuye un cuerpo a los colonizados a través de los adjetivos y de las metáforas que los deshumanizan, y que desde el punto de vista colonial les hacen interiorizar lo que no son. Entonces podremos establecer algunas categorías entrelazadas sobre los cuerpos de los que se habla en las novelas de Castro Soromenho: encontramos a los cuerpos utilitarios de los contratados que, por la violencia física ejercida sobre ellos, devienen cuerpos sangrientos; el cuerpo de sus castigadores, los sipaios y los capitas, que igualmente se inscribe en la galería de cuerpos utilitarios del régimen colonial, así como el cuerpo de las mujeres negras, que son cuerpos deseados; a la vez, sus cuerpos son denegados, ya que no son blancas. Igualmente denegados son los cuerpos de los contratados, denegados socialmente y a los que se da un cuerpo en grado cero, ya que por el trabajo podrán un día ser personas. O sea, podrán ser cuerpos creados, tal como el cuerpo de los sipaios o de los capitas lo es.

A través de la observación de la representación de los cuerpos de los 
colonizados, en un contexto asociado al colonialismo portugués bajo el régimen del Estado Nuevo, se valida la idea de que África es "the absolute otherness" de Europa en las representaciones sobre la diferencia, de acuerdo con Valentin Mudimbe (1994: 38). Es el polo expoliado de la humanidad a través del cual el polo expoliador legitima la colonización y crea el dominio de la colonialidad mediante la creación de la categoría general de "negros". A partir de ahí se crean diversas escalas categoriales del sujeto colonial. El cuerpo de los colonizados pertenece a la obra colonizadora, no sólo por la captación de las mentes, en las que se inscribe la idea de civilización, sino también por el trabajo forzado o por la utilización sexual de las mujeres negras, metáfora a menudo usada para el ejercicio del derecho de control de las tierras y de sus gentes en la construcción de la alteridad propio de la penetración colonial.

\section{BIBLIOGRAFÍA CITADA}

Amin, S. 2006. "De la crítica del radicalismo a la crítica del euroccidentalismo culturalista", en A. Césaire, Discurso sobre el Colonialismo: 95-146. Madrid: Akal.

Andrade, M. P. 1975. Antologia temática da Poesia Africana, Na Noite Grávida de Punhais. Vol. I. Lisboa: Livraria Sá da Costa Editora.

Bhabha, H. K. 1995. The Location of Culture. Londres y Nueva York: Routledge.

Bosi, A. 2003. Dialética da Colonização. São Paulo: Companhia das Letras.

Bourdieu, P. 1996. As Regras da Arte. Génese e Estrutura do Campo Literário. Lisboa: Editorial Presença.

Caetano, M. 1951. Tradições, Princípios e Métodos da Colonização Portuguesa. Lisboa: Agência Geral do Ultramar.

Castelo, C. 1998. "O Modo Português de Estar no Mundo", O Luso-Tropicalismo e a Ideologia Colonial Portuguesa (1933-1961). Oporto: Afrontamento.

Castro-Gómez, S. 2007. "Decolonizar la universidad. La hybris del punto cero y el diálogo de saberes", en S. Castro-Gómez y R. Grosfoguel (eds.), El Giro Decolonial. Reflexiones para una diversidad epistémica más allá del capitalismo global: 79-91. Bogotá: Siglo de Hombre Editores.

Césaire, A. 2006, "Discurso sobre el colonialismo", en Discurso sobre el Colonialismo: 1343. Madrid: Akal.

Clarence-Smith, G. 1990. O III Império Português (1825-1975). Lisboa: Teorema.

Dias, E. Costa. 2000. "Estado, estruturas políticas tradicionais e cidadania. O caso senegâmbiano", en J. M. Leite Viegas y E. Costa Dias (orgs.), Cidadania, Integração, Globalização: 37-59. Oeiras: Celta.

Dussel, E. 2010. "Meditaciones anti-cartesianas: sobre el origen del anti-discurso filosófico de la modernidad", en I. Rodríguez y J. Martínez (eds.), Estudios Transatlánticos Postcoloniales. I. Narrativas Comando / Sistemas Mundos: Colonialidad / Modernidad: 317-372. Barcelona: Anthropos.

Echeverría, B. 2007. "Imágenes de la "blanquitud"», en D. Lizarazo (coord.), Sociedades icónicas. Historia, ideología y cultura en la Imagen: 15-32. México: Siglo XXI. 
Fanon, F. 1952. Peau Noire, Masques Blancs. París: Éditions du Seuil.

Fanon, F. 2002 [1961]. Les Damnés de la Terre. París: La Découverte.

Freyre, G. 1966. "Interação eurotropical: aspectos de alguns dos seus vários processos, inclusive o lusotropical". Journal of Inter-American Studies 8 (1): 1-10.

Freyre, G. 2003 [1933]. Casa Grande e Senzala. São Paulo: Global Editora.

Grosfoguel, R. 2006. "Actualidad del pensamiento de Césaire: redefinición del sistemamundo y producción de utopía desde la diferencia colonial", en A. Césaire, Discurso sobre el Colonialismo: 147-172. Madrid: Akal.

Hall, S. 1996. "The West and the Rest: discourse and power", en S.Hall (ed.), Modernity: An Introduction to Modern Societies: 184-227. Londres: Blackwell Publishers.

Howson, A. 2004. The Body in Society. An Introduction. Cambridge: Polity Press.

Iniesta, F. 2001. El Planeta Negro. Aproximación Histórica a las Culturas Africanas. Madrid: Catarata.

Iser, W. 1993. The Fictive and the Imaginary. Charting Literary. Anthropology. Baltimore: The John Hopkins University Press.

Klobucka, A. 2008. "Lusotropicalism, race and ethnicity", en P. Poddar, R. S. Patke y L. Jensen (eds.), A Historical Companion to Postcolonial Literatures. Continental Europe and its Empires: 471-476. Edimburgo: Edinburgh University Press.

Labisa, A. dos Santos. 1958. "Interpenetração das economias", en Ministério do Ultramar (ed.), Colóquios de Política Ultramarina Internacional Relevante: 111-136. Lisboa: Junta de Investigações do Ultramar.

Lander, E. 2002. "Eurocentrism, modern knowledges, and the 'natural' order of global capital. Nepantla: Views from South 3 (2): 245-268.

Lalu, P. 2009. The Deaths of Hintsa. Postapartheid South Africa and the Shape of Recurring Pasts. Cape Town: HSRC Press.

Maldonado-Torres, N. 2007. "Sobre la colonialidad del ser: contribuciones al desarrollo de un concepto", en S. Castro-Gómez y R. Grosfoguel (eds.), El Giro Decolonial. Reflexiones para una diversidad epistémica más allá del capitalismo global: 127-167. Bogotá: Siglo de Hombre Editores.

Mbembe, A. 2003. "Necropolitics". Public Culture 15 (1): 11-40.

M'Bokolo, E. 1985. L'Afrique au XXe Siècle. Le Continent Convoité. París: Éditions du Seuil. Mudimbe, V. Y. 1994. The Idea of Africa. Bloomington: Indiana University Press.

Quijano, A. 2007. "Colonialidad del poder y clasificación social", en S. Castro-Gómez y R. Grosfoguel (eds.), El Giro Decolonial. Reflexiones para una diversidad epistémica más allá del capitalismo global: 93-126. Bogotá: Siglo de Hombre Editores.

Soromenho, C. 1979 [1957]. A Chaga. Lisboa: Livraria Sá da Costa Editora.

Soromenho, C. 1979 [1970]. Viragem. Lisboa: Livraria Sá da Costa Editora.

Soromenho, C. 2001 [1949]. Terra Morta. Porto: Campo das Letras.

Venâncio, J. C. 1993. Uma Perspectiva Etnológica da Literatura Angolana. "Chuva chove em cima da nossa terra de Luanda.. Lisboa: Ulmeiro.

Ventura, R. 1958. Nova Angola. s. 1.: s. n.

Fecha de recepción: 8 de noviembre de 2011

Fecha de aceptación: 13 de febrero de 2012 